Published in final edited form as:

Curr Opin Cardiol. 2008 July ; 23(4): 350-355.

\title{
Endothelin-1, aging and hypertension
}

\author{
Brian L. Stauffer ${ }^{a, b}, c$, Christian M. Westbya ${ }^{a}$, and Christopher A. DeSouza ${ }^{a}, b$ \\ aIntegrative Vascular Biology Laboratory, Department of Integrative Physiology, University of Colorado, \\ Boulder, USA \\ $\mathrm{b}$ Department of Medicine, University of Colorado, USA \\ cDenver Health Medical Center, Denver, Colorado, USA
}

\begin{abstract}
Purpose of review-Endothelin-1 system activation plays an important role in the etiology of atherosclerotic vascular disease. Aging and hypertension are two independent cardiovascular risk factors that have been shown to exhibit increased endothelin-1 system activation. This review focuses on the cardiovascular effects of the endothelin system, its relation to aging and hypertension, as well as potential treatment options.
\end{abstract}

Recent findings-Many of the cardiovascular complications associated with both aging and hypertension are attributable, in part, to endothelial dysfunction, particularly vasomotor dysregulation. To date most studies have focused on the effects of aging and hypertension on endothelium-dependent nitric oxide-mediated vasodilation. However, endothelin-1-mediated vasoconstrictor tone increases with age and contributes to the pathogenesis of hypertension. Pharmacologic approaches to reduce endothelin-1 system activation have produced limited results and are largely disease-specific. In contrast, regular aerobic exercise has been shown to be extremely effective at reducing endothelin-1 system activity.

Summary-Both aging and hypertension represent important cardiovascular disease risk factors that are characterized by increased endothelin-1-mediated vasoconstrictor tone. Future studies are needed to elucidate pharmacologic options for reducing endothelin-1 system activity especially in older hypertensive adults, though regular aerobic exercise must continue to be a point of emphasis for maintaining/improving vascular health.

\section{Keywords}

aging; endothelin-1; endothelium; hypertension

\section{Introduction}

Soon after the discovery that the vascular endothelium releases relaxing factors, Yanagisawa et al. [1] reported that endothelial cells also produce potent vasoconstrictor and pressor peptides referred to as endothelins. The endothelin family consists of four 21-amino-acid peptides: endothelin-1, endothelin-2, endothelin-3 and endothelin-4 [1,2]. Endothelin-1 is the most potent and predominant endothelin isoform in the human cardiovascular system and is now recognized to play a pivotal role in the regulation of vascular tone [3,4] and the etiology of atherosclerotic vascular disease [3].

Correspondence to Christopher DeSouza, PhD, Integrative Vascular Biology Laboratory, Department of Integrative Physiology, University of Colorado, 354 UCB, Boulder, CO 80309, USA Tel: +1 303492 2988; fax: +1 303492 6778; e-mail:

desouzac@colorado.edu. 


\section{Vascular effects of endothelin-1}

Produced by the proteolytic cleavage of big endothelin- 1 by endothelin converting enzyme (ECE), endothelial endothelin-1 is predominantly (>80\%) released abluminally toward the vascular smooth muscle. Indeed, local endothelin-1 concentrations within the vascular wall are more than 100-fold greater than circulating plasma levels [5]. The vascular actions of endothelin-1 are mediated by two distinct endothelin receptor subtypes: $\mathrm{ET}_{\mathrm{A}}$ receptors located exclusively on vascular smooth muscle and $\mathrm{ET}_{\mathrm{B}}$ receptors located on both the vascular smooth muscle and endothelial surfaces [2,6,7]. Binding of endothelin-1 to $\mathrm{ET}_{\mathrm{A}}$ and $\mathrm{ET}_{\mathrm{B}}$ receptors on vascular smooth muscle cells activates the phospholipase $\mathrm{C}$-inositol triphosphate pathway resulting in an increase in intracellular calcium causing phosphorylation of myosin kinase and, in turn, long-lasting smooth muscle cell contraction [3,4]. In contrast, activation of $\mathrm{ET}_{\mathrm{B}}$ receptors on endothelial cells stimulates the release of nitric oxide [through calcium-dependent endothelial nitric oxide synthase (eNOS) activation] resulting in vasodilation [3,4]. Thus, activation of $\mathrm{ET}_{\mathrm{B}}$ receptors can lead to dual vasoregulatory effects.

In addition to its vasoregulator actions, endothelin-1 system activation is now recognized to be involved in the pathogenesis of atherosclerotic vascular disease [3,7,8]. Potential mechanisms whereby increased endothelin- 1 system activity may contribute to atherogenesis include promotion of fibrous tissue formation [9] and inhibition of endothelial nitric oxide synthesis from increased intracellular endothelin-1 concentrations resulting in vasodilator dysfunction [10]. In addition, endothelin-1 stimulates platelet aggregation, cell adhesion molecule expression, and the growth and proliferation of vascular smooth muscle cells and mural fibroblasts, all-important early features of atherosclerosis $[4,11]$. Endothelin- 1 also activates leukocyte chemotaxis and inflammation in the vessel wall by stimulating cytokines such as interleukin- 6 and tumor necrosis factor- $\alpha$ [4] as well as proinflammatory mediators such as NF-kB [12], central factors involved in the inflammatory component of atherosclerosis [11].

Aging and hypertension represent two major independent risk factors for cardiovascular disease (CVD). Many of the cardiovascular complications associated with both aging and hypertension are attributable, at least in part, to endothelial dysfunction, particularly vasomotor dysregulation [13]. Although the majority of studies (in humans) have focused on the deleterious effects of aging and hypertension on endothelium-dependent nitric oxide-mediated vasodilation, it has become increasingly apparent that both conditions are associated with greater endothelin-1 vasoconstrictor activity. Indeed, the development of pharmacologic agents that selectively and nonselectively block $\mathrm{ET}_{\mathrm{A}}$ and $\mathrm{ET}_{\mathrm{B}}$ receptors has provided a means of assessing, in vivo, the activity of endogenous endothelin- 1 and the potential contribution of endothelin-1 to vasomotor derangement and disease pathogenesis. Recent studies in adult humans utilizing selective and nonselective endothelin-1 receptor antagonists have indicated an important role of endothelin-1-dependent vasoconstriction with aging [14. $]$ and the pathophysiology of human hypertension [15-17,18,19]. For example, Cardillo et al. [16] reported that hypertensive patients demonstrate greater vasodilator response to selective $\mathrm{ET}_{\mathrm{A}}$ receptor blockade, indicating enhanced endogenous endothelin-1 vasoconstrictor tone, compared with normotensive controls. Moreover, in a follow-up study [15] the same group of investigators showed that blockade of endothelin-1 receptors improved acetylcholine-induced endothelium-dependent vasodilation in hypertensive patients, demonstrating that increased endothelin-1 activity contributes to the vasomotor dysfunction associated with hypertension. Similar findings in older compared with young adults have recently been reported by Van Guilder et al. [14*]. The comparable forearm blood flow response to selective $\mathrm{ET}_{\mathrm{A}}$ receptor blockade with aging and hypertension is shown in Fig. 1. 
The realization that endothelin-1 essentially contributes to a number of cardiovascular disorders spawned specific pharmacotherapy aimed at reducing the action of the peptide. Data from laboratory and clinical trials have reported many potentially promising therapeutic benefits of targeting the endothelin-1 system. Experimentally, administration of endothelin-1 receptor blockade prevents and restores endothelial vasomotor dysfunction and structural vascular changes with atherosclerosis [20-22], reduces infarct size [23], and improves survival in heart failure [24]. In addition, selective and nonselective endothelin-1 receptor antagonists reduce ischemic brain injury in animal models of stroke [25,26]. In clinical studies, congestive heart failure patients treated with nonselective $\mathrm{ET}_{\mathrm{A} / \mathrm{B}}$ receptor antagonists demonstrate improved systemic and pulmonary hemodynamics resulting in enhanced cardiac index [27, 28] and a reduction in symptoms [29]. Moreover, endothelin-1 receptor antagonism has been shown to increase vasodilator tone of epicardial coronary arteries in patients with coronary artery disease [30].

There is little clinical data regarding the efficacy of suppressing endothelin-1 system activity in older adults or hypertensive patients. However, there are several classes of drugs that have theoretical benefit and deserve discussion in this forum as well as the exceptional benefit that can be derived from regular aerobic exercise.

\section{Endothelin converting enzyme inhibitors}

There are currently no data demonstrating clinical efficacy of preventing or treating hypertension solely with ECE activity inhibition. In fact, the development of these compounds (now in preclinical to phase II clinical trials) lags significantly behind the development of endothelin receptor antagonists (spanning preclinical trials to clinical use for pulmonary artery hypertension). Most ECE inhibitors are part of dual (compounds such as CGS 26303 and SLV 306) or triple (SCH54470, CGS 35601) vasopeptidase inhibitor compounds with action on neprylisin with or without angiotensin converting enzyme inhibition. Indeed, one of these combined inhibitors, CGS 35601, has demonstrated efficacy in decreasing blood pressure (BP) in animal models of essential hypertension [31,32]. Unfortunately, limitations to this approach such as broad interference with other enzymatic pathways leading to side effects like angioedema have diminished the overall enthusiasm for this class of compounds and promoted the exploration of the alternative approach, specifically endothelin receptor antagonism. Provided the limitations of ECE inhibition are not insurmountable, additional efficacy data is certainly necessary in older adults with hypertension for it is possible that a greater benefit will be realized in this population with evidence of increased activity of the endothelin system $\left[33^{\circ}, 34^{\circ}\right]$.

\section{Endothelin receptor antagonists}

Three classes of endothelin-1 receptor antagonists are currently in development [35], nonselective receptor antagonists and $\mathrm{ET}_{\mathrm{A}}$ as well as $\mathrm{ET}_{\mathrm{B}}$ selective antagonists. As it is generally believed that the $\mathrm{ET}_{\mathrm{B}}$ receptors mediate the beneficial cardiovascular effects such as endothelin-1 clearance, natriuresis, nitric oxide release and antiproliferative effects there is little evidence that $\mathrm{ET}_{\mathrm{B}}$ selective blockade will provide clinical benefit in systemic hypertension and this will not be further addressed. In contrast, bosentan, a nonselective endothelin receptor antagonist, and sitaxsentan, a selective $\mathrm{ET}_{\mathrm{A}}$ receptor blocker, reduce systemic $\mathrm{BP}$ in patients with mild-to-moderate primary hypertension $\left[36,37,38^{\bullet}, 39,40\right]$. The magnitude of the decrease $(\sim 6-11 \mathrm{mmHg}$ systolic and $4-8 \mathrm{mmHg}$ diastolic) was generally dose-dependent in these preliminary studies. Other than in salt-sensitive hypertension, which may be a special case that responds particularly well to nonselective $\left(\mathrm{ET}_{\mathrm{A}} / \mathrm{ET}_{\mathrm{B}}\right)$ blockade, there are several potential benefits to $\mathrm{ET}_{\mathrm{A}}$ receptor antagonism over non-selective antagonism. First, early data demonstrates a lower incidence of transaminase elevation in adults with 
hypertension [37]. Second, the magnitude of the BP reduction is lower in trials with a nonselective antagonist [36]. Finally, there is evidence that $\mathrm{ET}_{\mathrm{A}}$ selective antagonists preserve renal function in hypertensive patients with chronic kidney disease [39] and act synergistically with angiotensin converting enzyme inhibitors (ACEI) on the kidney through an $\mathrm{ET}_{\mathrm{B}}$ receptormediated mechanism [41]. Although none of these studies specifically targeted older adults, this constellation of characteristics is especially attractive for the older population with a higher prevalence of hypertensive renal disease and adverse drug reactions.

\section{Statins and endothelin-1}

HMG CoA reductase inhibitors ('statins') in general have been shown to block the endothelin-1 system through a variety of mechanisms. For example, in-vitro studies have shown that statins inhibit isoprenylation of Rho GTPase, thus blocking the membrane localization and activation of the protein. In addition, statins reduce the synthesis of endothelin- 1 and the expression of its precursor preproET-1 mRNA. Statins also prevent the downregulation of eNOS mRNA and protein levels associated with oxidized low-density lipoprotein (oxLDL). Importantly, this effect of statins on eNOS was dependent on mevalonate but completely independent of cholesterol lowering or the presence of oxLDL. This suggests that a product of mevalonate metabolism other than cholesterol may play a role in controlling preproET-1 levels [42]. Unfortunately, none of the large statin trials demonstrating improvements in primary or secondary cardiovascular event rates reported BP before and after therapy. However, a recent meta-analysis evaluating 20 smaller statin trials containing 828 patients demonstrated a statistically significant decrease in systolic BP and a trend toward a decrease in diastolic BP with statin treatment $\left[43^{\circ}\right]$. The magnitude of the decrease due to statin therapy was directly related to the pretreatment BP. The average decrease was $4 / 1 \mathrm{mmHg}$ in patients with a starting $\mathrm{BP}$ of more than 130/80 $\mathrm{mmHg}$. Although this change appears minimal, modest changes of 2 $\mathrm{mmHg}$ in systolic BP in the Antihypertensive and Lipid-Lowering Treatment to Prevent Heart Attack Trial (ALLHAT) trial [44] were associated with a 15\% lower stroke rate and a 19\% lower rate of heart failure whereas a $4 / 4 \mathrm{mmHg}$ drop in BP in the Hypertension Optimal Treatment (HOT) study [45] resulted in a 50\% reduction in cardiovascular events in diabetic patients. There is currently no data on the BP response to statins in older adults under elevated endothelin-1 vasoconstrictor tone and minimal evidence for a possible synergistic role of statins in the control of hypertension [46]. This is a potential lucrative area for future research regarding other benefits of statin use.

\section{Calcium channel blockers and endothelin-1}

In animal models, L-type calcium channel blockers decrease the vasoconstrictor effect of endothelin-1 on the vasculature. Over 15 years ago Kiowski et al. [47], in an elegant study, demonstrated for the first time that acute administration of the calcium channel antagonists nifedipine and verapamil abolished the endothelin-1-vasoconstrictor response in healthy adults. At that time the mechanism of endothelin-1 action was incompletely understood. Recently a study $\left[48^{\circ}\right]$ by the same group demonstrated that chronic oral nifedipine use blunts the endothelin-1 mediated vasoconstrictor response in middle-aged adults with essential hypertension independently of BP lowering. Moreover, the treatment effect was augmented in the hypertensive patients under elevated basal endothelin-1-mediated vasoconstrictor tone compared with normotensive controls. Extrapolation of these data to older adults with hypertension under considerably higher endothelin-1-mediated vasoconstrictor tone may suggest the calcium channel antagonist nifedipine would offer substantial potential for prevention of endothelin-1-mediated vascular complications. Additional investigation into the benefit of this and other calcium channel antagonists is necessary in this high-risk population. 


\section{Other pharmacologic agents and endothelin-1}

Although there is currently no data regarding the direct influence of other pharmacologic agents on the endothelin system in states associated with elevated endothelin-1-mediated vasoconstrictor tone, such as older adults with hypertension, several currently prescribed agents have theoretical benefit in suppressing endothelin-1 expression or its effect on the vasculature. Endothelin-1-stimulating factors include angiotensin II (Ang II), vasopressin, norepinephrine, isoprostane 8-epi-prostaglandin $\mathrm{F}_{2 \alpha}$, aging, insulin, and oxLDL [49]. Endothelin-1 may be stimulated by exogenous Ang II [50] and presumably by endogenous Ang II in some models of hypertension [51]. The role of ACEI or angiotensin receptor antagonists in mitigating the endothelin system in humans remains to be determined. Adrenergic stimulation exerts a pathologic growth effect on the heart through an endothelin-mediated pathway [52]. It remains to be determined whether endothelin activation occurs through the $\beta$-adrenergic receptor. If so, $\beta$-adrenergic antagonists may exert some of their beneficial effects through the suppression of endothelin-1 activation.

\section{Exercise and endothelin-1}

Regular aerobic exercise is associated with a reduction in CVD morbidity and mortality [5355]. One of the possible mechanisms by which regular aerobic exercise reduces the risk of CVD is through its availing effects on vasomotor function. Indeed, improved vascular vasomotor function has been linked to a reduction in cardiovascular events [56]. Several studies [57] have shown that aerobic exercise training improves endothelium-dependent vasodilation in healthy older adults as well as patients with hypertension. For example, 12 weeks of moderate aerobic exercise training have been shown to reverse the age-related loss in endothelial vasodilator function in previously sedentary men. In a recent study [14$\left.{ }^{\circ}\right]$, we demonstrated that moderate aerobic exercise also reduces endothelin-1-mediated vasoconstrictor tone. Exerciseinduced reductions in endothelin-1 system activation may contribute significantly to the known beneficial affects of exercise in preventing/treating hypertension $[58,59]$ and reducing the risk of atherosclerosis $[53,55,60]$. Habitual aerobic exercise is an important lifestyle intervention for improving vascular health in all adults that must be encouraged by clinicians with the same zeal as adherence to pharmacological treatment.

\section{Conclusion}

Although much attention has focused on the effects of aging and hypertension on endotheliumdependent vasodilation, the effects of endothelin-1-mediated vasoconstrictor tone on vascular health and disease should not be overlooked. Indeed, there is accumulating evidence that endothelin-1 system activity increases with advancing age, is involved in the primary etiology of hypertension, and contributes to endothelial dysfunction and the development of atherosclerotic vascular disease. The endothelin-1 system represents an important target for therapeutic interventions aimed at improving endothelial function and reducing cardiovascular disease. Both lifestyle and pharmacologic approaches are feasible options to accomplish this important goal.

Acknowledgements

The present work was supported in part by National Institutes of Health awards HL077450, HL076434, and MO1 RR00051 and American Heart Association awards 0840167N, 0555678Z and 076582Z.

\section{References and recommended reading}

Papers of particular interest, published within the annual period of review, have been highlighted as: 
- of special interest

$\bullet$ of outstanding interest

Additional references related to this topic can also be found in the Current World Literature section in this issue (p. 425).

1. Yanagisawa M, Kurihara H, Kimura S, et al. A novel potent vasoconstrictor peptide produced by vascular endothelial cells. Nature 1988;332:411-415. [PubMed: 2451132]

2. Masaki T, Kimura S, Yanagisawa M, Goto K. Molecular and cellular mechanism of endothelin regulation. Implications for vascular function. Circulation 1991;84:1457-1468. [PubMed: 1655302]

3. Miyauchi T, Masaki T. Pathophysiology of endothelin in the cardiovascular system. Annu Rev Physiol 1999;61:391-415. [PubMed: 10099694]

4. Luscher TF, Barton M. Endothelins and endothelin receptor antagonists: therapeutic considerations for a novel class of cardiovascular drugs. Circulation 2000;102:2434-2440. [PubMed: 11067800]

5. Kedzierski RM, Yanagisawa M. Endothelin system: the double-edged sword in health and disease. Annu Rev Pharmacol Toxicol 2001;41:851-876. [PubMed: 11264479]

6. Haynes WG, Strachan FE, Gray GA, Webb DJ. Forearm vasoconstriction to endothelin-1 is mediated by ETA and ETB receptors in vivo in humans. J Cardiovasc Pharmacol 1995;26(Suppl 3):S40-S43. [PubMed: 8587426]

7. Dashwood MR, Tsui JC. Endothelin-1 and atherosclerosis: potential complications associated with endothelin-receptor blockade. Atherosclerosis 2002;160:297-304. [PubMed: 11849651]

8. Hopfner RL, Gopalakrishnan V. Endothelin: emerging role in diabetic vascular complications. Diabetologia 1999;42:1383-1394. [PubMed: 10651255]

9. Guarda E, Myers PR, Brilla CG, et al. Endothelial cell induced modulation of cardiac fibroblast collagen metabolism. Cardiovasc Res 1993;27:1004-1008. [PubMed: 8221756]

10. Lavallee M, Takamura M, Parent R, Thorin E. Crosstalk between endothelin and nitric oxide in the control of vascular tone. Heart Fail Rev 2001;6:265-276. [PubMed: 11447301]

11. Ross R. Atherosclerosis-an inflammatory disease. N Engl J Med 1999;340:115-126. [PubMed: 9887164]

12. Schiffrin EL. Role of endothelin-1 in hypertension and vascular disease. Am J Hypertens 2001;14:83S-89S. [PubMed: 11411770]

13. Taddei S, Virdis A, Mattei P, et al. Hypertension causes premature aging of endothelial function in humans. Hypertension 1997;29:736-743. [PubMed: 9052889]

- 14. Van Guilder GP, Westby CM, Greiner JJ, et al. Endothelin-1 vasoconstrictor tone increases with age in healthy men but can be reduced by regular aerobic exercise. Hypertension 2007;50:403-409. [PubMed: 17576858] of special interestThis is the first study to demonstrate an increase in endothelin system activity in otherwise healthy older adults. The data suggest that vasoconstrictor tone is enhanced with aging similarly to hypertension. Importantly, a program of moderate aerobic exercise is a viable therapy in reversing this age-related dysfunction

15. Cardillo C, Campia U, Kilcoyne CM, et al. Improved endothelium-dependent vasodilation after blockade of endothelin receptors in patients with essential hypertension. Circulation 2002;105:452456. [PubMed: 11815427]

16. Cardillo C, Kilcoyne CM, Waclawiw M, et al. Role of endothelin in the increased vascular tone of patients with essential hypertension. Hypertension 1999;33:753-758. [PubMed: 10024340]

17. McEniery CM, Wilkinson IB, Jenkins DG, Webb DJ. Endogenous endothelin-1 limits exerciseinduced vasodilation in hypertensive humans. Hypertension 2002;40:202-206. [PubMed: 12154114]

18. Nohria A, Garrett L, Johnson W, et al. Endothelin-1 and vascular tone in subjects with atherogenic risk factors. Hypertension 2003;42:43-48. [PubMed: 12756218]

19. Touyz RM, Schiffrin EL. Role of endothelin in human hypertension. Can J Physiol Pharmacol 2003;81:533-541. [PubMed: 12839265]

20. Moreau P, d'Uscio LV, Shaw S, et al. Angiotensin II increases tissue endothelin and induces vascular hypertrophy: reversal by ET(A)-receptor antagonist. Circulation 1997;96:1593-1597. [PubMed: 9315552] 
21. Best PJ, McKenna CJ, Hasdai D, et al. Chronic endothelin receptor antagonism preserves coronary endothelial function in experimental hypercholesterolemia. Circulation 1999;99:1747-1752. [PubMed: 10190886]

22. Barton M, Haudenschild CC, d'Uscio LV, et al. Endothelin ETA receptor blockade restores NOmediated endothelial function and inhibits atherosclerosis in apolipoprotein E-deficient mice. Proc Natl Acad Sci U S A 1998;95:14367-14372. [PubMed: 9826706]

23. Grover GJ, Dzwonczyk S, Parham CS. The endothelin-1 receptor antagonist BQ-123 reduces infarct size in a canine model of coronary occlusion and reperfusion. Cardiovasc Res 1993;27:1613-1618. [PubMed: 8287438]

24. Sakai S, Miyauchi T, Kobayashi M, et al. Inhibition of myocardial endothelin pathway improves long-term survival in heart failure. Nature 1996;384:353-355. [PubMed: 8934519]

25. Barone FC, White RF, Elliott JD, et al. The endothelin receptor antagonist SB 217242 reduces cerebral focal ischemic brain injury. J Cardiovasc Pharmacol 1995;26(Suppl 3):S404-S407. [PubMed: 8587428]

26. Tatlisumak T, Carano RA, Takano K, et al. A novel endothelin antagonist, A-127722, attenuates ischemic lesion size in rats with temporary middle cerebral artery occlusion: a diffusion and perfusion MRI study. Stroke 1998;29:850-857. [PubMed: 9550522]

27. Torre-Amione G, Young JB, Durand J, et al. Hemodynamic effects of tezosentan, an intravenous dual endothelin receptor antagonist, in patients with class III to IV congestive heart failure. Circulation 2001;103:973-980. [PubMed: 11181472]

28. Schalcher C, Cotter G, Reisin L, et al. The dual endothelin receptor antagonist tezosentan acutely improves hemodynamic parameters in patients with advanced heart failure. Am Heart $\mathbf{J}$ 2001;142:340-349. [PubMed: 11479476]

29. Spieker LE, Noll G, Ruschitzka FT, Luscher TF. Endothelin receptor antagonists in congestive heart failure: a new therapeutic principle for the future? J Am Coll Cardiol 2001;37:1493-1505. [PubMed: 11345356]

30. Wenzel RR, Fleisch M, Shaw S, et al. Hemodynamic and coronary effects of the endothelin antagonist bosentan in patients with coronary artery disease. Circulation 1998;98:2235-2240. [PubMed: 9826308]

31. Daull P, Blouin A, Belleville K, et al. Triple VPI CGS 35601 reduces high blood pressure in lowrenin, high-salt Dahl salt-sensitive rats. Exp Biol Med (Maywood) 2006;231:830-833. [PubMed: 16741007]

32. Daull P, Benrezzak O, Arsenault D, et al. Triple vasopeptidase inhibition normalizes blood pressure in conscious, unrestrained, and spontaneously hypertensive rats. Am J Hypertens 2005;18:16061613. [PubMed: 16364833]

-33. Daull P, Jeng AY, Battistini B. Towards triple vasopeptidase inhibitors for the treatment of cardiovascular diseases. J Cardiovasc Pharmacol 2007;50:247-256. [PubMed: 17878751] of special interestA current review concerning the efficacy of a combined triple vasopeptidase inhibitor targeting the three most important systems implicated in blood pressure control; renin —angotensin - aldosterone, natriuretic peptides and kinin, and endothelin

- 34. Kirkby NS, Hadoke PW, Bagnall AJ, Webb DJ. The endothelin system as a therapeutic target in cardiovascular disease: great expectations or bleak house? Br J Pharmacol 2008;153:1105-1119. [PubMed: 17965745] of special interestA review examining the divergent success of current therapies targeting the endothelin system in cardiovascular diseases

35. Battistini B, Berthiaume N, Kelland NF, et al. Profile of past and current clinical trials involving endothelin receptor antagonists: the novel "-sentan" class of drug. Exp Biol Med (Maywood) 2006;231:653-695. [PubMed: 16740981]

36. Krum H, Viskoper RJ, Lacourciere Y, et al. The effect of an endothelin-receptor antagonist, bosentan, on blood pressure in patients with essential hypertension. Bosentan hypertension investigators. N Engl J Med 1998;338:784-790. [PubMed: 9504938]

37. Nakov R, Pfarr E, Eberle S. Darusentan: an effective endothelinA receptor antagonist for treatment of hypertension. Am J Hypertens 2002;15:583-589. [PubMed: 12118903]

-38. Black HR, Bakris GL, Weber MA, et al. Efficacy and safety of darusentan in patients with resistant hypertension: results from a randomized, double-blind, placebo-controlled dose-ranging study. J 
Clin Hypertens (Greenwich) 2007;9:760-769. [PubMed: 17917503] of special interestThis randomized, double-blind, placebo-controlled study demonstrated the efficacy of the selective ETA receptor antagonist Darusentan in otherwise treatment-resistant hypertension

39. Goddard J, Johnston NR, Hand MF, et al. Endothelin-A receptor antagonism reduces blood pressure and increases renal blood flow in hypertensive patients with chronic renal failure: a comparison of selective and combined endothelin receptor blockade. Circulation 2004;109:1186-1193. [PubMed: 14981006]

40. Calhoun DA, Renfoe K, Alper A. Oral sitaxsentan, an endothelin-a selective receptor antagonist, reduces systemic blood pressure in patients with mild-to-moderate primary hypertension [abstract]. Circulation 2000;102:147. [PubMed: 10889123]

41. Goddard J, Eckhart C, Johnston NR, et al. Endothelin A receptor antagonism and angiotensinconverting enzyme inhibition are synergistic via an endothelin B receptor-mediated and nitric oxidedependent mechanism. J Am Soc Nephrol 2004;15:2601-2610. [PubMed: 15466264]

42. Hernandez-Perera O, Perez-Sala D, Navarro-Antolin J, et al. Effects of the 3-hydroxy-3methylglutaryl-CoA reductase inhibitors, atorvastatin and simvastatin, on the expression of endothelin-1 and endothelial nitric oxide synthase in vascular endothelial cells. J Clin Invest 1998;101:2711-2719. [PubMed: 9637705]

- 43. Strazzullo P, Kerry SM, Barbato A, et al. Do statins reduce blood pressure? A meta-analysis of randomized, controlled trials. Hypertension 2007;49:792-798. [PubMed: 17309949] of special interestA well designed meta-analysis demonstrating the effectiveness of statin therapy on blood pressure reduction in hypercholesterolemic patients

44. Siragy HM. Major outcomes in high-risk hypertensive patients randomized to angiotensin-converting enzyme inhibitor or calcium channel blocker vs. diuretic: the Antihypertensive and Lipid-Lowering Treatment to Prevent Heart Attack Trial (ALLHAT). JAMA 2002;288:2981-2997. [PubMed: 12479763]

45. Hansson L, Zanchetti A, Carruthers SG, et al. Effects of intensive blood-pressure lowering and lowdose aspirin in patients with hypertension: principal results of the Hypertension Optimal Treatment (HOT) randomised trial. HOT Study Group. Lancet 1998;351:1755-1762. [PubMed: 9635947]

46. King DE, Mainous AG III, Egan BM, et al. Use of statins and blood pressure. Am J Hypertens 2007;20:937-941. [PubMed: 17765132]

47. Kiowski W, Luscher TF, Linder L, Buhler FR. Endothelin-1-induced vasoconstriction in humans. Reversal by calcium channel blockade but not by nitrovasodilators or endothelium-derived relaxing factor. Circulation 1991;83:469-475. [PubMed: 1846783]

- 48. Sudano I, Virdis A, Taddei S, et al. Chronic treatment with long-acting nifedipine reduces vasoconstriction to endothelin-1 in essential hypertension. Hypertension 2007;49:285-290. [PubMed: 17178974] of special interestOne of only two studies examining the effects of chronic calcium antagonism and endothelin system activity in hypertensive patients

-49. Feldstein C, Romero C. Role of endothelins in hypertension. Am J Ther 2007;14:147-153. [PubMed: 17414582] of special interestThis current review examines the influence of endothelin-1 on organ systems known to be involved in mediating blood pressure

50. Hong HJ, Chan P, Liu JC, et al. Angiotensin II induces endothelin-1 gene expression via extracellular signal-regulated kinase pathway in rat aortic smooth muscle cells. Cardiovasc Res 2004;61:159-168. [PubMed: 14732213]

51. Medeo Modesti P, Zecchi-Orlandini S, Vanni S, et al. Release of preformed Ang II from myocytes mediates angiotensinogen and ET-1 gene overexpression in vivo via AT1 receptor. J Mol Cell Cardiol 2002;34:1491-1500. [PubMed: 12431448]

52. Moser L, Faulhaber J, Wiesner RJ, Ehmke H. Predominant activation of endothelin-dependent cardiac hypertrophy by norepinephrine in rat left ventricle. Am J Physiol Regul Integr Comp Physiol 2002;282:R1389-R1394. [PubMed: 11959681]

53. Powell KE, Thompson PD, Caspersen CJ, Kendrick JS. Physical activity and the incidence of coronary heart disease. Annu Rev Public Health 1987;8:253-287. [PubMed: 3555525]

54. Manson JE, Stampfer MJ, Hennekens CH, Willett WC. Body weight and longevity. A reassessment. JAMA 1987;257:353-358. [PubMed: 3795418] 
55. Blair SN, Kohl HW III, Paffenbarger RS Jr, et al. Physical fitness and all-cause mortality. A prospective study of healthy men and women. JAMA 1989;262:2395-2401. [PubMed: 2795824]

56. Levine GN, Keaney JF Jr, Vita JA. Cholesterol reduction in cardiovascular disease. Clinical benefits and possible mechanisms. N Engl J Med 1995;332:512-521. [PubMed: 7830734]

57. Higashi Y, Sasaki S, Kurisu S, et al. Regular aerobic exercise augments endothelium-dependent vascular relaxation in normotensive as well as hypertensive subjects: role of endothelium-derived nitric oxide. Circulation 1999;100:1194-1202. [PubMed: 10484540]

58. Seals DR, Tanaka H, Clevenger CM, et al. Blood pressure reductions with exercise and sodium restriction in postmenopausal women with elevated systolic pressure: role of arterial stiffness. J Am Coll Cardiol 2001;38:506-513. [PubMed: 11499745]

59. Chobanian AV, Bakris GL, Black HR, et al. The Seventh Report of the Joint National Committee on Prevention, Detection, Evaluation, and Treatment of High Blood Pressure: the JNC 7 report. JAMA 2003;289:2560-2572. [PubMed: 12748199]

60. American Heart Association. Heart and stroke facts: 2007 statistical supplement. American Heart Association; Dallas, TX: 2008. 


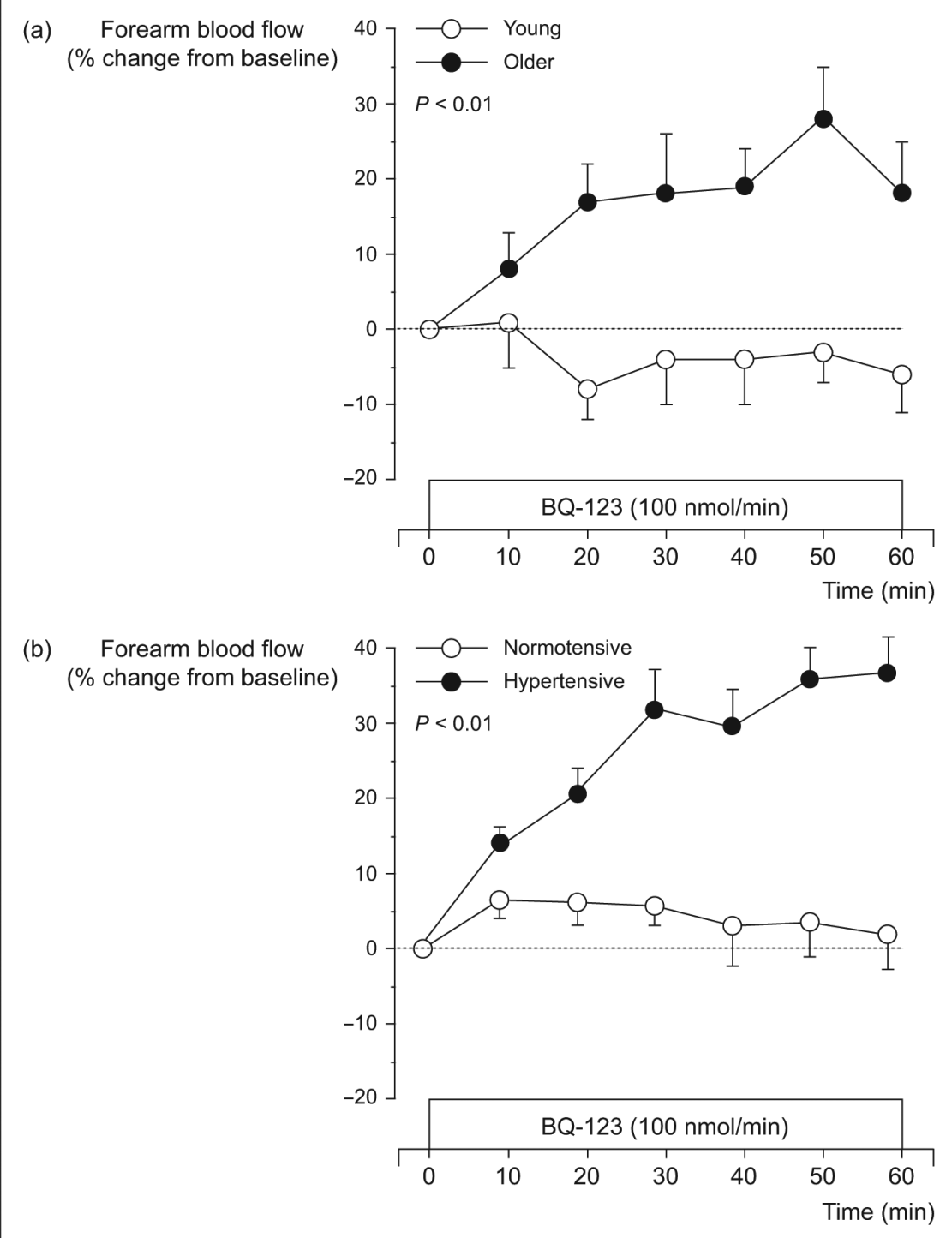

Figure 1. Forearm blood flow responses to selective $\mathrm{ET}_{\mathrm{A}}$ receptor blockade with $\mathrm{BQ123}$ in (a) young $(26 \pm 1$ year) and older (62 \pm 2 years) men and (b) normotensive $(47 \pm 1 \mathrm{yr})$ and hypertensive $(51 \pm$ 2 yr) adults

Vasodilator response in both the older and hypertensive adults is indicative of increased endothelin-1-mediated vasoconstrictor tone [(b) adapted from [16]]. Values are mean \pm SEM. 